\title{
Fake Egyptian Currency Detection System using Texture and Shape Characteristics
}

\author{
W. K. EISaid \\ Lecturer in CS \\ Mansoura University, Egypt
}

\begin{abstract}
Recently, due to the development in computer software, laser printers and scanners, counterfeiting has become an urgent issue. As a result, distinguishing fake currency from genuine one using new technologies has become more important. This research paper presents a new feature extraction based system for detecting the fake Egyptian paper currency. The process of extracting features is separately performed on both sides of the original and the sample version of the currency image. The obtained features are divided into two parts namely; texture features and shape features. The currency detection decision for each side is independently acquired by similarity measurement. Simulation results show that the proposed system can be used effectively in financial organizations and various commercial applications.
\end{abstract}

\section{Keywords}

Egyptian currency, Fake currency, Currency detection, Feature extraction, GLCM.

\section{INTRODUCTION}

Updating the financial system is essential for ensuring the economic prosperity and permanently preserving the social harmony [1]. In many countries, the reserve banks are the central banks owned by the government. Their main responsibilities include managing the national monetary policy, issuing notes and coins, guaranteeing their design and security, and controlling the circulation level continuously[2].

Over the history, currency issuers suffered the risk of counterfeiting. Thus, the counterfeiting currency amount in circulation threatens the usability rate and confidence degree in currency. Actually, confidence affects the intrinsic value and the stability level of the currency. Despite the increasing use of electronic currency in digital payments services, currency notes remain in abundance. In fact, the value of currency notes is higher than coins exposing them to counterfeiting and high economic risks[3].

Currently, the development in modern technology plays a vital role in the improvement of currency counterfeiting level making the fake currency appear to be too real[4]. With the progress of the current banking services, paper currency verification methods has become ever more necessary in modern technologies such as automated teller machines, automatic selling goods machines, etc[5].

The need for un-manual detection systems to determine the authenticity of currency stimulated many researchers to design and develop high accuracy, reliable and high processing speed methods[6].To be effective, the fake currency detection system in digital world should satisfy the two important targets. Firstly, to distinguish counterfeit currency note from genuine one quickly and correctly. Secondly, to recognize currency note from any side[7].
Generally, any digital system for currency detection shares the following main steps: image acquisition, edge detection, image segmentation, feature extraction and image comparison[8]. The key step and the most difficult task in any currency detection system is feature extraction process. It aims to analyze and identify the most important attributes of currency image on challenging cases(old notes, damaged notes, etc), also under various conditions(lighting, background, etc) $[1,5,9,10]$.

In pattern recognition, feature extraction is the method of reducing the number of resources necessary to characterize the huge amount of data. Commonly, the visual image features are divided into two types: general purpose and specific domain. The former includes color, texture and shape features while the latter is used in many special applications and includes fingerprints and human faces features only[11].

This research paper focuses on fake currency detection. The contribution of current paper is introducing a digital system for verifying the authenticity level of Egyptian paper currency. In the proposed system, two types of image feature vectors are created. The first type consists of Gray-Level Cooccurrence Matrix(GLCM) and its related texture features: contrast, correlation, energy and homogeneity. The second type composed of binary-level shape features extractors: eccentricity, extent and solidity.

The following parts of the paper are structured as follows. The next part provides a brief review of the monetary system development in Egypt. Section 3 presents fake Egyptian currency detection system. Section 4 describes design and implementation scenarios of proposed system. Section 5 discusses the experimental results. Finally, conclusions are briefly introduced in the last section.

\section{HISTORICAL OVERVIEW}

An overview of the Egyptian monetary history can be listed as follows[12]:

It was not until 1834 when Egypt decided to have a specified financial unit. That year, a decree was officially launched to mint a new Egyptian monetary unit in the form of gold and silver riyals which was only under the government control. In 1836, the Egyptian pound was minted and circulated but it didn't meet the increasing needs of transactions and foreign trade. The foreign currencies were also used at fixed exchange rates determined by the law. Yet, variation in the value of silver in addition to adopting the gold as a monetary standard for foreign transactions, especially with the United Kingdom, resulted in adopting gold as the only standard rather than silver after using them both together for 30 years. When Egypt suffered a financial crisis due to the accumulation of foreign debts, there was an urgent need for the monetary reform law in 1885 by which gold standard became the basis of the Egyptian monetary system, and Egypt started to adopt a unified currency. But the new minted gold coins didn't satisfy 
the increasing needs of foreign trade and transactions so again some foreign coins, including the pound sterling, were used. The pound sterling which had a larger value than its gold content remained the main medium for foreign exchange and the monetary system no longer depended on the ordinary gold system. In 1898, the National Bank in Egypt was founded and granted the privilege to issue the first Egyptian banknotes that could be turned into gold. Both the Egyptian banknotes and the gold pound sterling remained used as the medium of exchange until 2/8/1914. On that date, a decree was issued to assign the Egyptian paper made banknotes as the basic currency of Egypt with a legal tender. Consequently, the amount of banknotes increased from 11.6 million pounds in 1915 to 35570.0 million pounds by the end of 1980 further to 38320.0 million pounds by the end of 1999 .

The development stages of security features include the following:

a) In 1930, the Egyptian banknotes were protected with a watermark.

b) By the end of 1968, a metallic thread was used in the banknotes issued by the central bank of Egypt(CBE) to prevent counterfeiting instead of dependence on the complexity of colors in addition to the use of holograms and other features.

c) In July 19th, 1960, Law No.250 was issued but later modified by Law No.377 in the same year. This law delegated the CBE to be responsible for issuing the Egyptian banknotes. Then the CBE established its own printing house instead of printing the banknotes abroad. It also printed the banknotes of some other Arab central banks.

d) With the increasing requirements of banknotes in a growing economy that adopted the global economy policy, the CBE issued notes of large denominations. It issued the denominations of $20 \mathrm{LE}$ in May 1979, $100 \mathrm{LE}$ in May 1979 and LE 50 in March 1993. After that, the LE 200 is launched with large size. In 2009, the LE 200 size was modified to its current size.

\section{PROPOSED SYSTEM}

In the proposed system, two versions of Egyptian paper currency image are required. The first is the reference version of currency image. The second is the sample version of currency image that undergoes the authentication process. The main steps involved in the proposed algorithm for the presented currency detection system can be summarized as shown below in the following diagram:

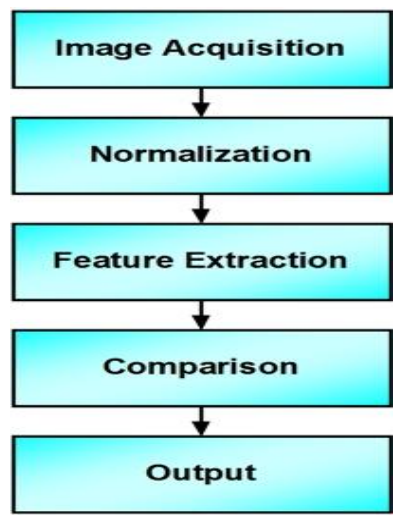

Fig.1: Design flow of proposed methodology
The entire processes (not shown in the above diagram) of each step will be discussed in detail as follows:

\subsection{Image Acquisition}

Loading the currency images upon the target computer is the first procedure in the workflow sequence. Both reference and test paper currency image are acquired by using a simple scanner or digital camera without reducing quality of currency image.

\subsection{Normalization}

Usually the scanned currency image through scanner or the captured currency image through digital camera is too big in size. So as to decrease the calculations, currency image dimensions are changed to the desired size.

\subsection{Feature Extraction}

The attributes of normalized currency images are firstly extracted before currency verification process. Secondly, the feature vectors that describe texture and shape are created to be used later in comparison process. The feature vectors computation steps are explained in detail as follows:

\subsubsection{Texture Feature Extraction}

To determine the texture properties of Egyptian paper currency image, the workhorse of image texture analysis methods -GLCM- is used to calculate several texture measurements. The full steps behind the texture analysis based on the proposed approach include:

Step 1: Read the reference and the test currency image.

Step 2: Perform the following steps on both currency images separately:

Step 3: Convert the color currency image form the RGB model to the grayscale model.

Step 4: Create the GLCM from the grayscale version of the currency image in four directions $\left(0^{\circ}, 45^{\circ}, 90^{\circ}\right.$ and $\left.135^{\circ}\right)$.

Step 5: Derive the statistical parameters form the GLCM: contrast, correlation, energy and homogeneity.

Step 6: Compute the mean value of the GLCM contrast vector.

Step 7: Compute the mean value of the GLCM correlation vector.

Step 8: Compute the mean value of the GLCM energy vector.

Step 9: Compute the mean value of the GLCM homogeneity vector.

Step 10: Store all the obtained mean values into 1-D texture feature vector.

\subsubsection{Shape Feature Extraction}

To analyze the shape attributes of Egyptian paper currency image, various properties of regions in the currency image are extracted. The full steps behind the shape analysis based on the proposed approach include:

Step 1: Read the reference and the test currency image.

Step 2: Apply the following steps on both currency images separately:

Step 3: Convert the color currency image form the RGB model to the grayscale model. 
Step 4: Find a global threshold for all pixels in the grayscale image.

Step 5: Turn the grayscale image into a binary image using the calculated threshold value.

Step 6: Label the binary image using 8-connected components.

Step 7: Measure the three basic properties: eccentricity, extent and solidity of labeled regions in the binary image.

Step 8: Compute the mean value of the eccentricity vector.

Step 9: Compute the mean value of the extent vector.

Step 10: Compute the mean value of the solidity vector.

Step 11: Store all the obtained mean values into 1-D shape feature vector.

\subsection{Comparison}

To decide the authenticity of the test version of currency image, a side-by-side comparison is firstly performed with the reference version of currency image using the extracted features at both levels of texture and shape. In texture level, the texture similarity ratio(TSR) is calculated according to the following formula:

$$
\begin{gathered}
\mathrm{T} 1=\mathrm{EQ}_{\mathrm{dist}}(\mathrm{TXT} 1, \mathrm{TXT} 2) ; \\
\mathrm{TSR}=[1-\mathrm{T} 1] * 100 \%
\end{gathered}
$$

Where,

TXT1: Texture feature vector of the reference currency image.
TXT2: Texture feature vector of the test currency image.

T1: Euclidian distance value between TXT1 and TXT2.

On the other hand, in shape level the shape similarity ratio(SSR) is calculated according to the following formula:

$$
\begin{gathered}
\mathrm{T} 2=\mathrm{EQ}_{\text {dist }}(\mathrm{SHP} 1, \mathrm{SHP} 2) ; \\
\mathrm{SSR}=[1-\mathrm{T} 2]^{*} 100 \%
\end{gathered}
$$

Where,

SHP1: Shape feature vector of the reference currency image.

SHP2: Shape feature vector of the test currency image.

T2: Euclidian distance value between SHP1and SHP2.

\subsection{Output}

The final outcome of the proposed currency detection system includes: texture similarity ratio, shape similarity ratio and either "The Egyptian Currency is Genuine" or "The Egyptian Currency is Fake".

\section{DESIGN AND IMPLEMENTATION}

The proposed system has been prototyped using matlab platform under windows 7(64-bit version) operating system. At the start-up of the application, the "splash screen" form shown in Figure. 2 is displayed. This form shows the research paper information(University, Faculty, Title and the Researcher's Name) to the system users while the proposed system is loading.

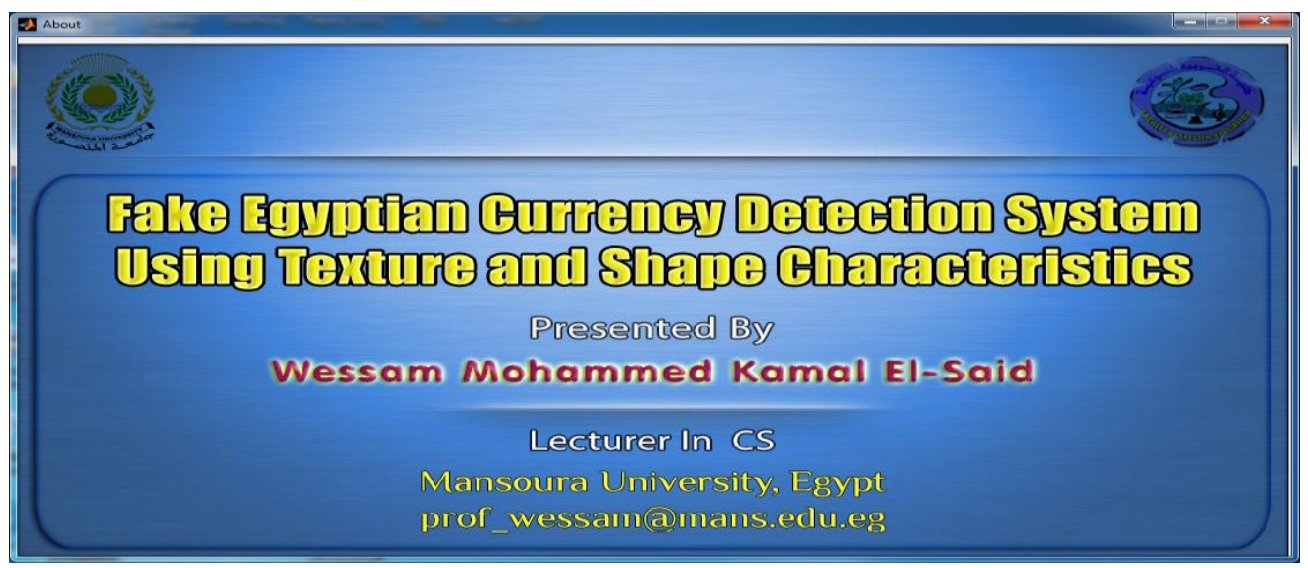

Fig.2: Snapshot of splash screen window

After a predefined time the previous system identification form is closed automatically and the "login" window is displayed. This form enables the authenticated users to access the proposed system by entering the correct login password The layout screen of login form is shown in Figure.3.

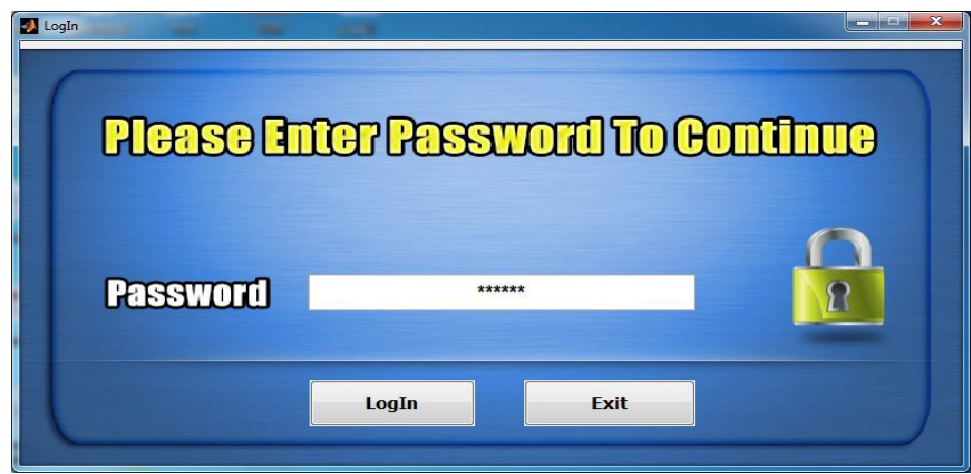

Fig.3: Snapshot of login window 
After entering the password in the related textbox and pressing the "login" button, the validation process is done. If the system user enters a valid password, the main form of the proposed system shown in Figure. 4 will be displayed.

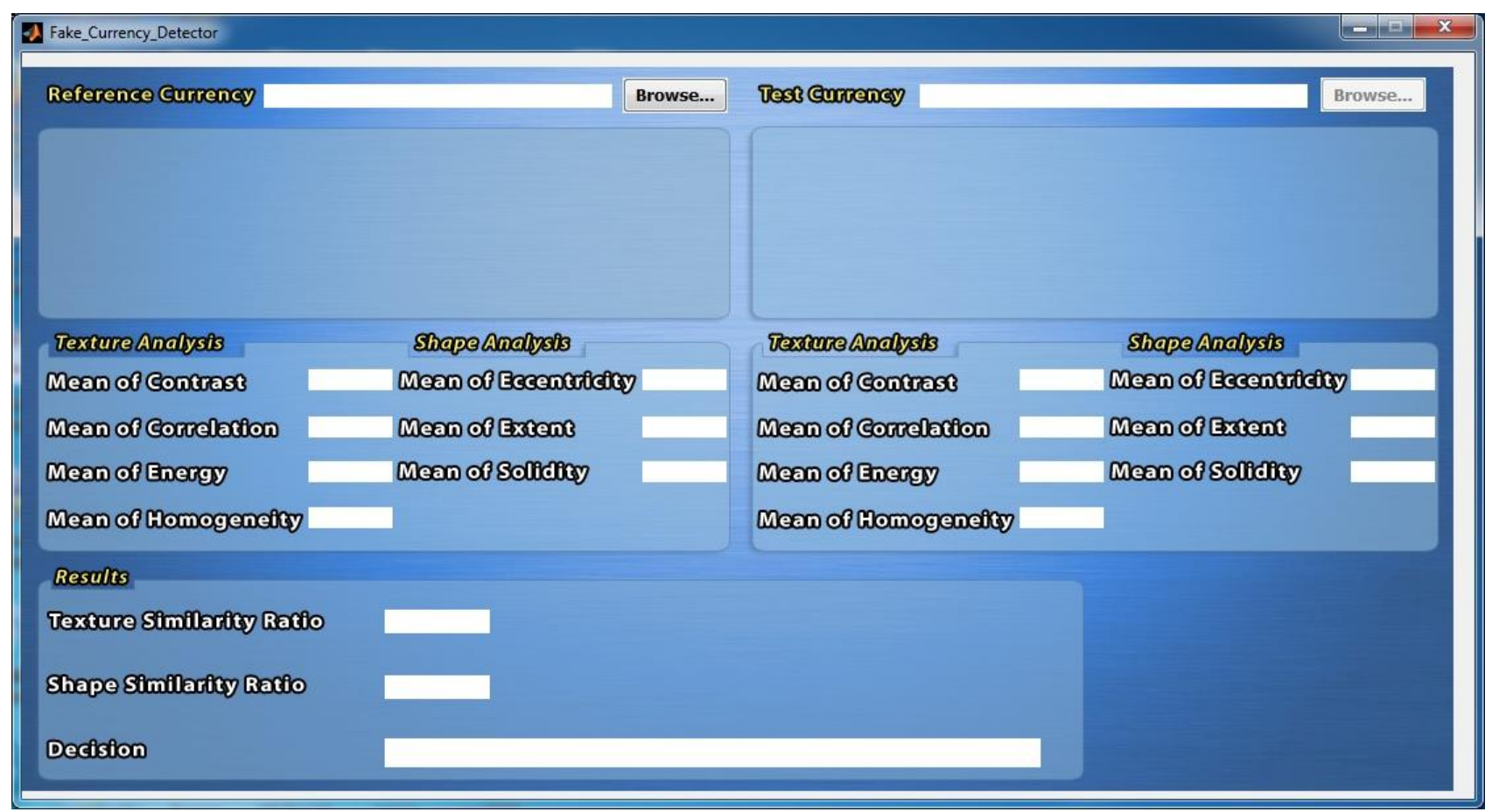

Fig.4: Snapshot for the main window of proposed currency detection system

Once the user presses the "browse" button in the left hand side, a pop-out box which enables the user to select the color image used as the reference currency will be presented. After that, the currency image features information will appear in the certain spaces, the selected image will be displayed on the axis designed for this purpose and the button "browse" in the right part will be converted to enable mode. The output of the current process is shown in Figure.5.

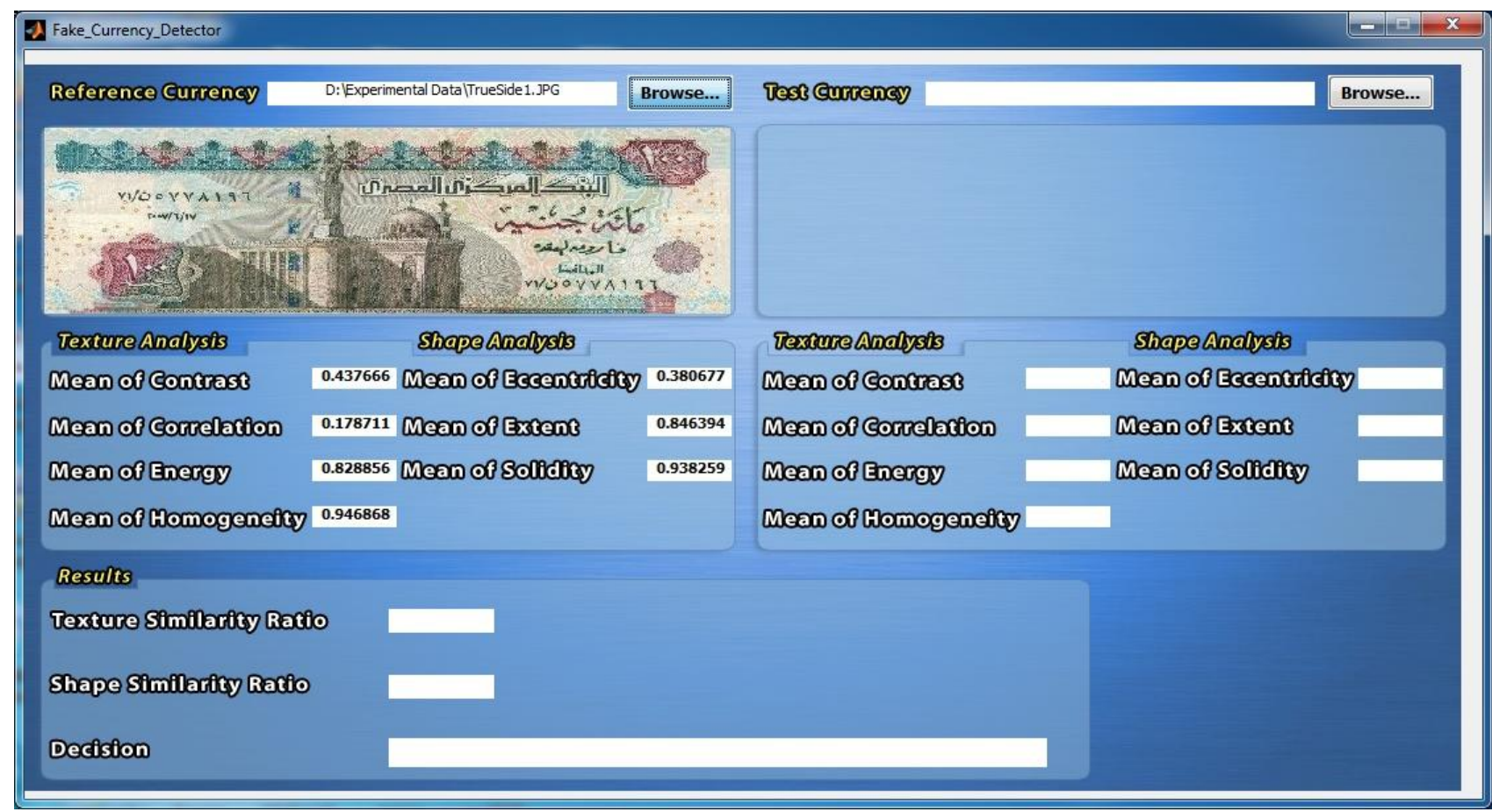

Fig.5: Snapshot for the main window after selecting the reference currency image

After the user clicks on the "browse" button in the right hand side, a pop-out box which enables the user to select the color image used as the test currency will be presented. After that, the currency image features information will appear in the certain spaces, the selected image will be displayed on the axis designed for this purpose and the button "start" will be converted to visible mode. The output of the current process is shown in Figure.6. 


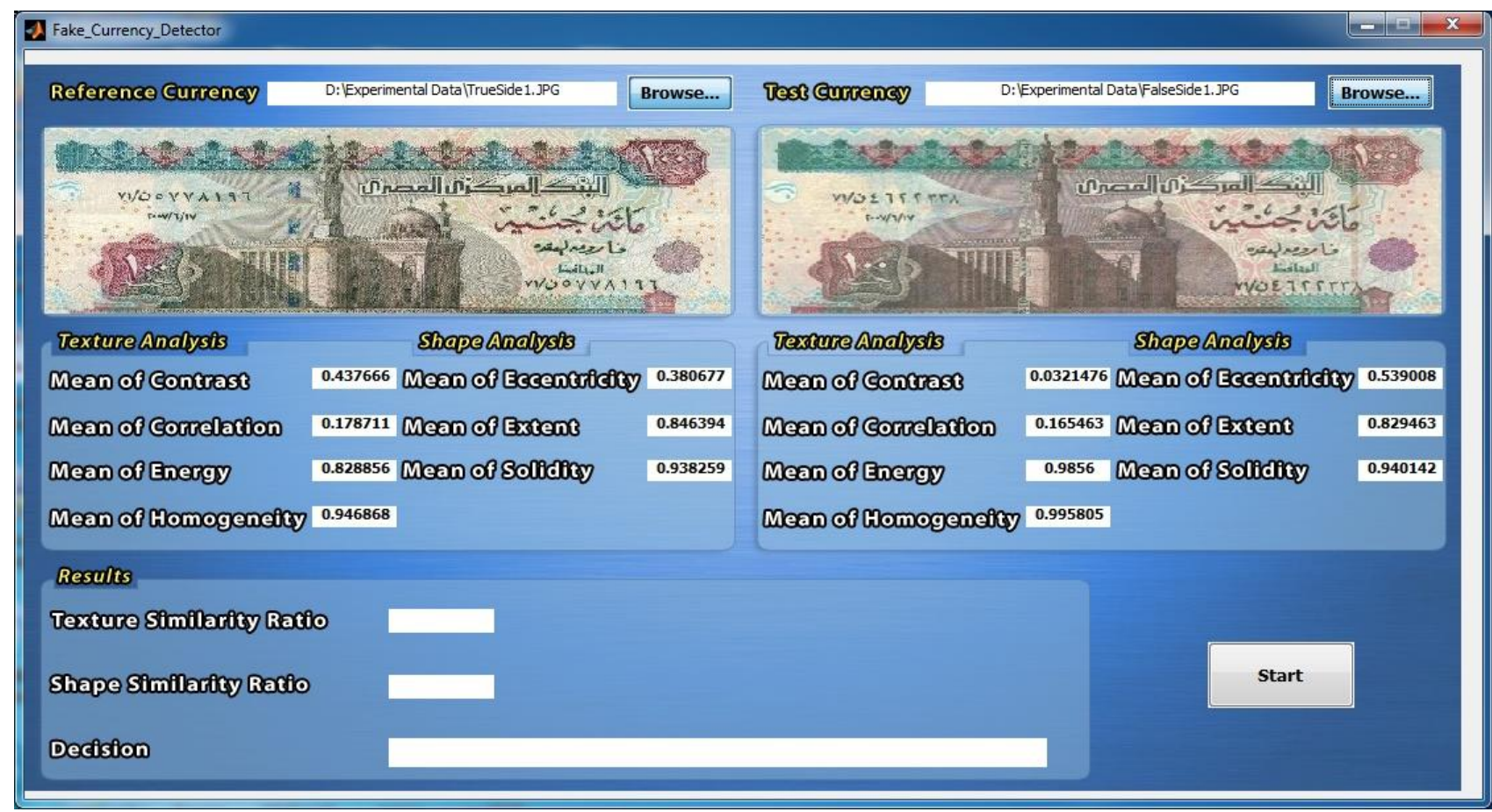

Fig.6: Snapshot for the main window after selecting the test currency image

Once the "start" button is pressed, the comparison process is performed on the features extracted from the reference currency image and the features extracted from the test currency image. After the comparison process is fully executed, the target results (texture similarity ratio, shape similarity ratio and decision) will appear in the certain spaces. The final output of the main window after the completion of all its items is shown in Figure.7.

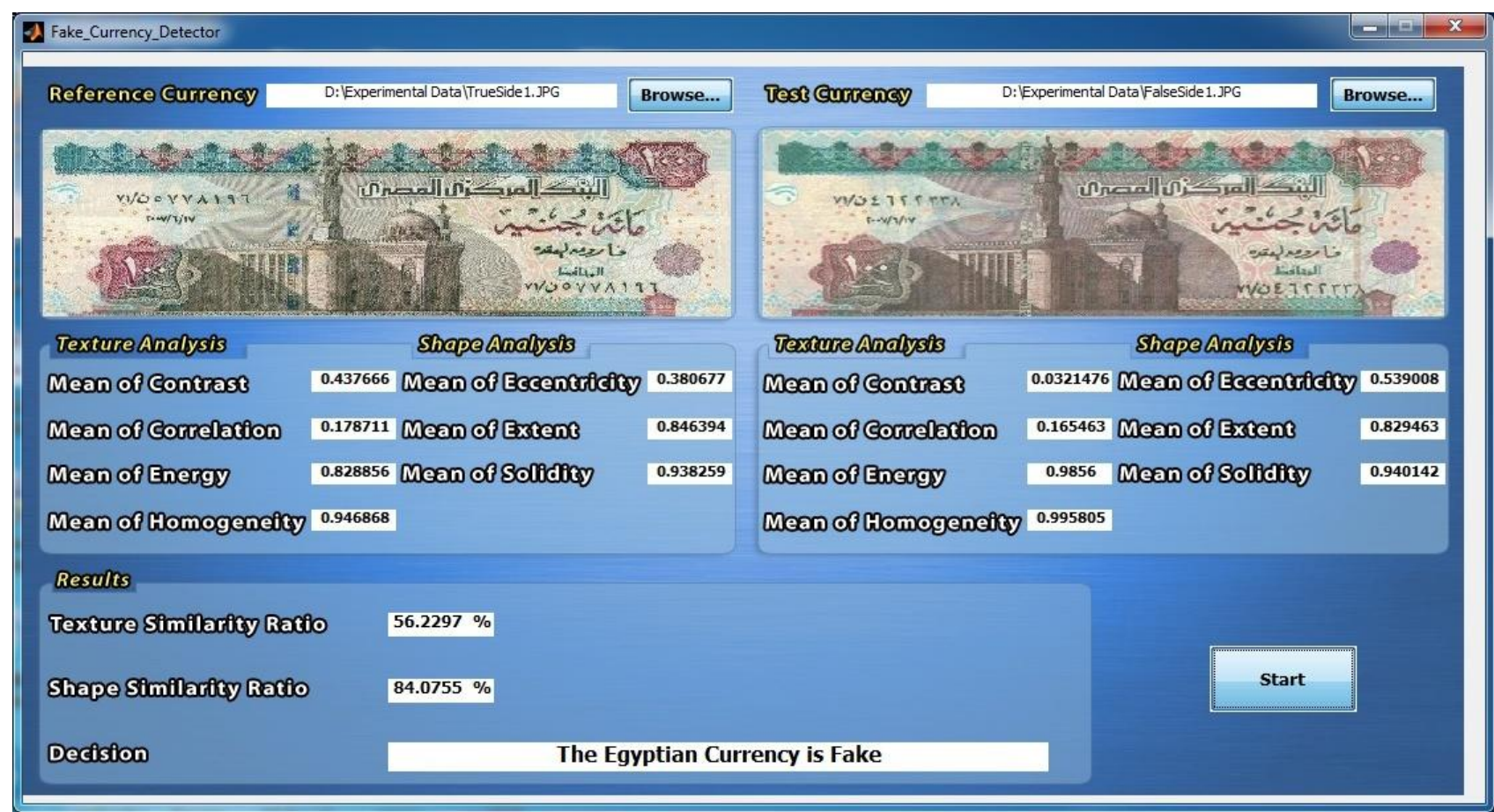

Fig.7: Snapshot for the final output of proposed currency detection system

\section{EXPERIMENTAL RESULTS}

To verify the effectiveness of the proposed work, several experiments are performed on a large sample of Egyptian paper currency. The sample includes different types of counterfeiting ranging from the simple to the complex levels. The features of acquired currency image under testing are compared with that of reference currency image at texture and shape level for both currency sides separately. All results are recorded, organized and summarized below in Table 1. 
Table 1. Obtained similarity ratios between reference currency and test currency

\begin{tabular}{|c|c|c|c|c|}
\hline \multirow{3}{*}{$\begin{array}{c}\text { Denomination } \\
\text { Value }\end{array}$} & \multicolumn{4}{|c|}{ Average } \\
\hline & \multicolumn{2}{|c|}{ Texture Similarity Ratio [ \%] } & \multicolumn{2}{|c|}{ Shape Similarity Ratio [ \%] } \\
\hline & Arabic Side & English Side & Arabic Side & English Side \\
\hline 5 EGP & 69.4871 & 78.4118 & 88.2316 & 90.1158 \\
\hline 10 EGP & 66.2808 & 58.4944 & 94.6967 & 89.1364 \\
\hline 20 EGP & 76.4377 & 72.3491 & 89.4724 & 93.4907 \\
\hline 50 EGP & 74.7577 & 71.4343 & 90.3333 & 88.2886 \\
\hline 100 EGP & 63.1392 & 61.5196 & 91.6021 & 92.2307 \\
\hline 200 EGP & 64.6524 & 69.3117 & 89.2401 & 87.5772 \\
\hline Total Average & 69.13 & 68.59 & 90.60 & 90.14 \\
\hline
\end{tabular}

Overall, the above results show that the proposed system achieved $100 \%$ accuracy rate to detect counterfeiting of Egyptian paper currency in texture and shape level for all test cases. In texture level, most of texture differences between the reference and the test currency image are easily recognized by the proposed texture approach. In shape level, the simple changes of shape details which usually can't be noticed by human eye are successfully identified by the proposed shape approach. From the obtained results, we conclude that designing the shape elements of Egyptian paper currency is easier than simulating the texture material.

\section{CONCLUSION}

This paper has discussed a digital system for verifying paper currency of Egypt. The proposed work is an effort to suggest an approach for extracting the important image features of Egyptian paper currency. The proposed approach uses two features vector of paper currency image including texture and shape. The texture features are extracted using Gray-Level Co-occurrence Matrix while the shape features are extracted using a set of common properties that describe connected image regions. Empirical results demonstrate that the proposed system is very efficient, more time saving and more accurate for verifying the authenticity level of Egyptian paper currency image. Future work will highlight refining the features chosen and developing the proposed system to help the blind.

\section{REFERENCES}

[1] Lawade, S. S., Hedau, G.S. and Ramgirwar, A.C., "Fake Currency Detection using Image Processing", International Journal of Research In Science \& Engineering, Volume 1 Special Issue 1, PP 321-327, March 2015 .

[2] Chambers, J., Yan, W., Garhwal, A. and Kankanhalli, M., "Currency Security and Forensics: A Survey", Multimedia Tools and Applications, Volume 74, Issue 11, PP 4013-4043, June 2015.

[3] Yan, W.Q., Chambers, J. and Garhwal, A.S., "An Empirical Approach for Currency Identification", Multimedia Tools and Applications, Volume 74, Issue 13, PP 4723-4733, July 2015.

[4] Ambadiyil, S., Reddy, S.T.R., Teja, R.B. and Pillai, M.V.P., "Banknote Authentication using Normalized Cross Correlation Method", Discovery Journal, Volume 44, Issue 205, PP 166-172, October 2015.
[5] Sowmyashree., Shetty, S., Ghotkar, T., Yadav, C. and Kanojiya, S., "Currency Recognition and Fake Note Detection", International Journal of Research in Engineering \& Advanced Technology (IJREAT), Volume 3, Issue 5, PP 179-182, Oct - Nov 2015.

[6] Mirza, R., Nanda, V., "Paper Currency Verification System based on Characteristic Extraction using Image Processing", International Journal of Engineering and Advanced Technology (IJEAT), Volume 1, Issue 3, PP 68-71, February 2012.

[7] Thakur, M., Kaur, A., "Neuro-Fuzzy based Fake Currency Detection System", International Journal of Advanced Research in Computer Science and Software Engineering, Volume 4, Issue 7, PP 358-365, July 2014.

[8] Chakraborty, K., Basumatary, J., Dasgupta, D., Kalita, J.C. and Mukherjee, S., "Recent Developments in Paper Currency Recognition System", International Journal of Research in Engineering and Technology(IJRET), Volume 02, Issue 11, PP 222-226, Nov 2013.

[9] Yadav, B.P., Patil, C.S., Karhe, R.R. and Patil, P.H., "Indian Currency Recognition and Verification System using Image Processing", International Journal of Advanced Research in Computer Science and Software Engineering, Volume 4, Issue 12, PP 943-947, December 2014.

[10] Venugopal, V., Thomas, D. and Prasad, A., "Indian Currency Recognizer and Counter System", International Journal of Innovative Technology and Exploring Engineering (IJITEE), Volume 4, Issue 5, PP 34-37, October 2014.

[11] Sai Prasanthi, B., Rajesh Setty, D.," Indian Paper Currency Authentication System using Image Processing", International Journal of Scientific Research Engineering \& Technology (IJSRET), Volume 4, Issue 9, PP 973-981, September 2015.

[12] Available at http://www.cbe.org.eg/English/, Viewed 5/April/2016 